\title{
EA16
}

\section{The Discovery and Appraisal of the Mzia Field,} Tanzania

N. Pike (BG Group), R.G.A. Baker* (BG Group), M.A. Owen (BG Group), C. Sirju (BG Group) \& I.R. Garden (BG Group)

\section{SUMMARY}

Mzia is a very large gas field, of Cretaceous age, located in the Ruvuma Basin within the Block 1 licence, offshore Tanzania (Figure 1).

In this presentation we will discuss how our understanding of the field has evolved from the initial identification of the prospect on 2D seismic data through to appraisal well drilling, with a particular emphasis on how the depositional setting has influenced the unusual sedimentology of the field. 


\section{Introduction}

Mzia is a very large gas field, of Cretaceous age, located in the Ruvuma Basin within the Block 1 licence, offshore Tanzania (Figure 1). BG is the operator of the block with a $60 \%$ interest; Ophir Energy plc and Pavilion Energy each hold 20\%. The discovery well, drilled in 2012, encountered deep-marine turbiditic sandstones of Cretaceous age; subsequently a further two appraisal wells have been drilled and production tests were conducted. The purpose of this presentation is to describe how our knowledge of the reservoir has developed through time, from the initial identification of the prospect and through the appraisal campaign.

\section{Discussion}

Mzia was initially identified on 2D seismic data and mapped in full based on 3D seismic survey shot in 2008, although at this point its prospectivity was considered to be less than the more obvious younger targets within the Tertiary, which exhibited clear attribute anomalies. Within Mzia, the attribute response was more equivocal; while a weak anomaly was observed its cause was debated due to concerns over the validity of the rock physics interpretation at this depth (nearly $3 \mathrm{~km}$ below mud line) as well as the possibility of tuning effects.

The structural setting of Mzia is also markedly different from the other fields discovered in Block 1 and Block 4 to date. While the Tertiary reservoirs are typically trapped where west to east trending slope canyon complexes are draped over structural highs, the Mzia attribute anomalies are orientated north-south parallel to the Seagap fault, a major strike slip structure still active today and perpendicular to the orientation of the current seafloor canyon system. The interpreted gas charged sands were mapped onlapping a confining slope to the west, with the eastern boundary of the anomaly being defined by the Seagap fault generally. A number of NW-SE trending en echelon normal faults, connected to the Seagap, further subdivide the field.

From the initial seismic interpretation, the reservoir was subdivided into three seismically resolvable units. The most prominent of these seismic anomalies was observed in the middle unit, still referred to today as the Middle Sand. This discovery well, drilled in early 2012, targeted only the middle and lower units. While initial LWD data hinted at the presence of reservoir, it was only after samples were collected and wireline data interpreted using advanced petrophysical workflows, that the extent of the net pay was revealed. Although both units were shown to be reservoir, it was in fact the lower unit, with the weaker seismic response that was found to have significantly higher net/gross and as a consequence more pay.

Based on this initial result, attention shifted to the Lower Sand unit, and the first appraisal well targeted this unit in a more axial part of the basin (bypassing both the Middle Sand and Upper Sands altogether). This well, Mzia-2, confirmed reservoir presence within the Lower Sand unit as well as encountering higher net/gross and net pay than the discovery well and a successful production test was subsequently performed. Having drilled an appraisal well located in the axial part of the depocentre, a decision was taken to drill the second appraisal well closer to the inferred source point and Mzia-3, which at this time was tentatively inferred to be from the north. This third well was extensively cored, with samples recovered from both the Lower and Middle sands, and a well test and PLT was conducted over the cored 
interval, confirming the deliverability of the reservoir and greatly improving our understanding of the flow characteristics of the different units.

The Mzia sands were deposited within a complex depositional system, our understanding of which has developed through time with multiple iterations of seismic data as well as log and core data from appraisal wells. Sediment provenance studies, combined with detailed seismic mapping, now suggest that the flow direction switched from south to north after the Lower Sand was deposited and the three packages identified initially have been divided further, into four distinct sedimentary packages, to produce a higher resolution view of the field. Core, log and biostratigraphic data are currently being reconciled with the seismic and combined with conceptual models from the modern environment as well as data from outcrop to improve our understanding of the field.

It is critical to understand how reservoir fluids and pressure are communicated through these different lithological packages and various studies are currently ongoing to address this issue. It is also important to better understand the relationship between seismic and reservoir quality; while initial studies indicate that only minor changes in reservoir parameters can account for the observed changes in the seismic response it is possible that future work may allow for more useful data may be extracted. The results of these various studies will help to better condition reservoir models of the field itself as well as have implications for similar prospects elsewhere.

\section{Acknowledgments}

Block 1 JV partners (BG Group, Ophir Energy plc, Pavilion Energy and TPDC) 


\section{EAGE}

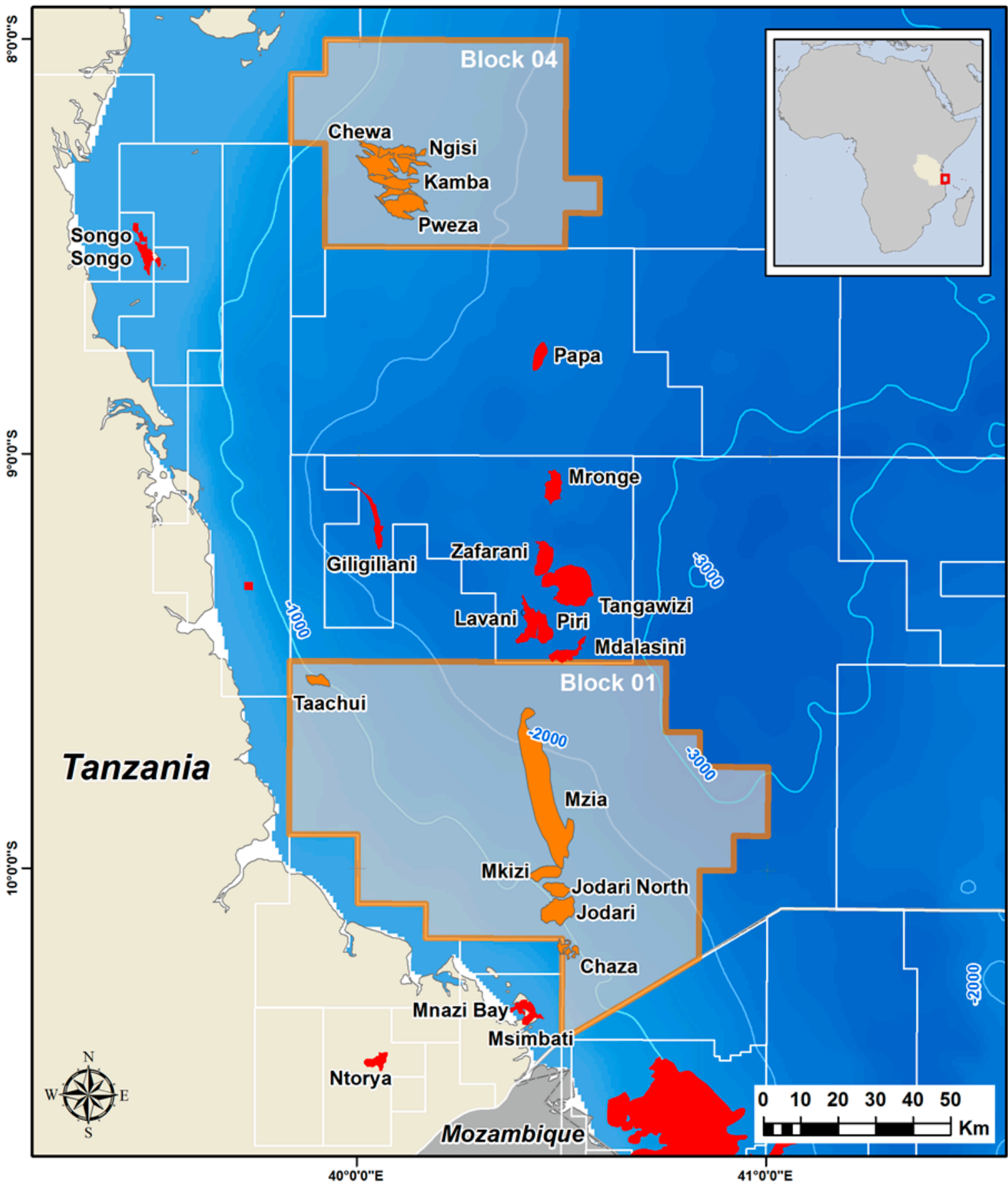

Figure 1 BG acreage offshore Tanzania showing the location of Mzia within Block 1. 